\title{
One Nation, Two Planning Systems? Spatial Planning and Multi-Level Policy Integration in Ghana: Mechanisms, Challenges and the Way Forward
}

\author{
Ransford A. Acheampong ${ }^{1}$ - Alhassan Ibrahim ${ }^{1}$
}

Published online: 13 November 2015

(C) The Author(s) 2015. This article is published with open access at Springerlink.com

\begin{abstract}
Effective integration across policy domains and between spatial scales is indispensable in dealing with the inherently complex process of policy formulation and implementation at all levels. In this paper, we examine the key features of Ghana's spatial planning system focusing on the mechanisms and challenges of policy integration in practice. We show that a combination of path dependence and recent reforms has inevitably created two distinctly separate planning systems: an established Development Planning System and a newly instituted Spatial Planning System. Under the established notion of the 'spatial' being distinctively separate from the 'socio-economic' in planning, these two systems deploy separate institutional and legal arrangements as well as policy instruments to accomplish the task of planning. Within this context, mechanisms to ensure effective policy integration were found to be weak and ineffective. Moreover, the absence of a tradition of strategic regional planning and a culture of strategic partnerships among local authorities, the lack of appropriate institutional arrangements and sustainable sources of finance and duplicitous institutional functions were the key barriers to effective integration within the new concept of hierarchical spatial planning. We argue that a new paradigm of integrated planning under a unified planning system is urgently needed as a pre-condition for effective multi-level policy integration. We suggest that some forms of institutional restructuring would be necessary to establish a tradition of integrated planning. Finally, we recommend the use of legally binding mechanisms to institutionalize and enforce a culture of strategic alliance among local governments in cross-cutting matters.
\end{abstract}

Keywords Spatial planning · Governance · Integration · Planning instruments · Mechanisms · Ghana

Ransford A. Acheampong

raa49@cam.ac.uk

1 University of Cambridge, Cambridge, UK 


\section{Introduction}

In many countries across the globe, spatial/land-use planning constitutes one of the established governance systems by which governments articulate and implement policies aimed at achieving an integrated and functional organization of activities, as well as regulating the type, location and timing of these activities at various spatial scales (Owens and Cowell 2011; Rotmans et al. 2000; Healey et al. 1997). Spatial planning embraces the task of integrating the economic, social and environmental dimensions of territorial strategies with the ultimate aim of ensuring that development outcomes are sustainable (Cullingworth and Nadin 2006; Vigar 2009; Roseland 2000). It is also viewed as a political resource providing a platform for consensus building towards a shared vision and development outcomes (Allmendinger and Haughton 2010). Working in tandem with markets, spatial planning could also be used to achieve a just and equitable distribution of economic development gains between regions in a country (Allmendinger 2009; Stead and Meijers 2009).

Invariably, the objective of spatial planning is intermediate to some wider policy goals relating to social welfare, environmental protection, economic growth and cultural conservation (Vigar et al. 2000). Given that divergent and often conflicting interests, visions and expectations characterise the processes leading to the formulation and implementation of policies, plans and strategies to achieve these goals, the need for integration across sectors and policy domains (i.e. horizontal integration) and between policy levels or scales (i.e. vertical integration) not only become crucial but also a prominent feature of spatial planning (Nadin 2007; Counsell et al. 2006). Across Europe for example, the need for improved and effective policy integration has culminated in restructuring (Counsell et al. 2006), rescaling (Vigar 2009; Allmendinger and Haughton 2007) or reinforcement and modernisation (OECD 2001) of planning systems over the years.

In Ghana, the history of planning dates back to the early twentieth century when the first National Development Plan — the Guggisberg plan (1920-1930)—was implemented under the British colonial rule (Fuseini and Kemp 2015). Much is not known about the planning system then except planning being a centralized activity executed on administrative basis without the participation of the public. The post-independence era saw a drive to broaden the spatial coverage of planning and to strengthen institutional capacities, leading to the establishment of planning department across the country (Fuseini and Kemp 2015). Similar to the pre-independence era, planning in postindependent Ghana was very centralized with the national government preparing a series of development plans which emphasised economic transformation through industrialization and infrastructure development.

Among her contemporaries in Africa, Ghana is one of the few countries that is recognised to have National Development Frameworks with spatial references (UNHabitat 2014) and at the same time gone through a number of changes towards improving its planning system. Even so, Ghana's Spatial Planning System for many years has been criticised as weak and ineffective in delivering its objectives (Yeboah 2002; Owusu 2008). In a bid to invigorate and modernize her planning system, Ghana in 2007, introduced a new three-tier spatial planning model that would allow for spatial planning at the national, regional and local levels of administration (MESTI 2011). Before these reforms, spatial planning largely remained a local level activity concerned 
with the preparation of local land use/ sub-division plans and development control. In addition, a tradition of Development Planning aimed at formulating medium-term plans to bring about socio-economic development, with particular emphasis on poverty reduction had long existed.

Over the years, the inception of the new Spatial Planning System has culminated in the formulation of several spatial planning instruments at different spatial scales, including a National Spatial Development Framework, a Regional Spatial Development Framework for the oil region in the Western part of the country; a Sub-Regional Spatial Development Framework for the second largest city, Kumasi and its surrounding districts as well as many Structure Plans and Local Plans at the city and neighbourhood scales, respectively. With the proliferation of spatial planning instruments at various scales under the new Spatial Planning System and the existence of many sectoral plans and policies under an established Development Planning System, arise the practical challenge of effectively synchronising visions, goals and strategies across policy domains and spatial scales over time.

In this paper, we critically examine the mechanisms of vertical and horizontal integration in contemporary spatial planning in Ghana. To this end, we place our analysis of multi-level integration within the wider context of the national governance structure by focusing on the authorities and competencies of spatial planning at the national and sub-national levels as well as the accompanying institutional and legal milieu. In particular, we identify the gap(s) between integration as embedded in the design of the planning system and integration in action. On the basis of these, we identify challenges and propose ways in which the system could potentially be improved to deliver its objectives in an effective and efficient manner.

In the sections that follow, we discuss the concept of integration within spatial planning systems and set the framework for our analysis. This is followed with a discussion of the approach adopted for the study in section three. In the penultimate section, we focus the analysis on policy integration in Ghana's spatial planning system discussing the mechanisms, practices and challenges. We end with some recommendations on how integration could be fostered for an efficient and effective planning system in Ghana.

\section{The Concept of Integration in Planning Systems}

The concept of integration is broad and used across a wide range of disciplines concerned with public policy, resulting in conceptual controversies around its meaning in the literature. Policy integration is often conflated with, and used alongside other related terminologies such as policy coordination, co-operation, policy coherence and cross-cutting policy-making, among others, to imply a holistic approach that avoids fragmented decision making by integrating different but interrelated policies (Meijers and Stead 2004). Cowell and Martin (2003) used the term 'joining up', to imply similar notion of policy linkages and consistency. Stead and Jong (2006: (4) offer a comprehensive definition in which they referred to integration as 'the management of cross-cutting issues in policy-making that transcends the boundaries of established policy fields, and which do not correspond to the institutional responsibilities of individual departments'. 
Within the context of spatial planning, integration is a deliberate and concerted process involving different actors. It involves the use of various formally established or informal mechanisms and instruments to synchronise cross-cutting and often conflicting goals towards a shared vision articulated in the form of policies, plans and projects, to influence the distribution of population, land use and economic activities in space. Thus, fundamentally, integration is an important task and strength of spatial governance at different levels (Albrechts 2006) and resonates with the modern system of political thinking and management theory which emphasise democracy, participation and pluralism (Osborne 2006). Integration in spatial planning is essential to promote consensus building through participation: avoid policy conflicts, contradictions and redundancy, to enhance balanced development and facilitate governments' overall policy goals (Stead and Meijers 2009; Peters 1998; Newman 2008; Counsell et al. 2006; Allmendinger 2003).

\section{Types and Dimensions of Policy Integration}

There are two main mutually linked types of integration in the spatial planning literature: vertical integration and horizontal integration. These overlap with formal governance structures and the accompanying administrative institutions which have authority and competencies in planning derived from various legislative instruments. Vertical integration is linked with the rescaling or subsidiary principle of government (Davoudi and Evans 2008) and takes place between actors and policies at different tiers of government from national to local or vice versa (Allmendinger and Haughton 2010; Cowell and Martin 2003; Vigar 2009). Horizontal integration occurs between and across sectoral policies of the same level and the institutions (i.e. departments, agencies etc.) that prepare them and see to their implementation (Vigar 2009; OECD 2001; Shaw and Lord 2007). Horizontal integration is essential to eliminating overlapping and duplicity of policy goals and effectively handling variety of issues that transcend beyond the boundary of a particular sector or spatial unit in order to attain efficiency, effectiveness and responsiveness to community needs whilst saving public money (Cowell and Martin 2003; Peters 2006).

Both vertical and horizontal integration are linked in four dimensions namely: time, space, actors and issues (Underdal 1980). The time dimension is concerned with whether integration is pursued on a long-term or short-term basis; the space dimension concerns the geographical extent at which policy or integration is covered; the range or proportion of actors included in policy integration forms the actor dimension whilst the range and aspect of issues and their interdependencies incorporated in the integration process form the issues dimensions.

\section{Mechanisms of Policy Integration}

Peters (2006) identified three main mechanisms of integration: markets, networks and hierarchical mechanisms. Market mechanism of integration is linked to the invisible hand aphorism of Adam Smith and follows that integration would occur automatically whether in the private sector or within public policy when there is exchange of goods and services as well as bargaining. Network mechanism of integration is concerned with the interaction that emerges between individuals and organizations within the 
same policy level. Indicated by Peters as a natural mechanism, it has the potential to avoid policy conflicts by creating a mutual ground of understanding and co-ordinating public policies. Hierarchical mechanisms are more of a vertical integration in which there is a system of authority, legal provisions and instruments to achieving policy goals at different spatial scales.

In practice, these mechanisms are not deployed in isolation. Rather, they work in tandem with each other to ensure effective policy integration. For example, in many countries, hierarchical mechanisms are deployed in the form of spatial planning instruments such as National Policy and Perspectives: Strategic Regional Plans, Frameworks or Master plans and Local/Subdivision plans, to achieve consistency between policy goals and objectives at the various spatial scales. Legislations in the form of Acts, Ordinances and Decrees often accompany these planning instruments and provide the legal basis for their enforcement and compliance.

In addition, legislations dictate institutional mandates and responsibilities and spell out the imperatives of integration as well as the relevant rules, procedures and channels of policy coordination. A typical example is the so-called 'duty to cooperate arrangement' in the UK which places legal duty on local planning authorities, county councils and public bodies to engage constructively, actively and on an on-going basis in plan preparation in the context of strategic cross-boundary matters (see Merritt and Stubbs 2012).

Moreover, the various mechanisms could be organised by way of formalized intergovernmental and inter-departmental committees to take comprehensive, multi-sectoral, long-range view of spatial issues, define priorities and coordinate the plethora of sectoral policies (ESPON project 2.3.2 2006). In the absence of formal rules and procedures, integration across policy domains may occur through a more voluntary or ad-hoc and often less formal arrangements on 'as-and-when-is-needed' basis (Silva and Acheampong 2015). These arrangements usually make use of pre-existing informal networks or new ones that evolve among officials working in separate government departments to meet a perceived need for coordination (Silva and Acheampong 2015).

As with many public policy endeavours, there are gaps between theory and practice in achieving integration in spatial planning. The complex nature of institutional settings, the difficulty in sustaining collectivism and the conflicting nature of spatial planning itself, present major challenges to achieving effective integration in practice (Newman 2008; Allmendinger and Haughton 2010). Again, as noted by Faludi (2000), the anxiety of planners that their plans are much too indicative rather than binding do present a major challenge to effective integration. Other sources of challenge to effective integration include barriers in technical language in different sectors, the lack of coordinating bodies and of financial allocation systems, increasing levels of competition among sectors and institutions grounded in the perception that some policy sectors are important than others, the absence of political will or commitment and a lack of awareness and expertise (Stead and Meijers 2009; Stead and de Jong 2006; United Nations 2008; Peters 2006).

\section{Method}

Despite the long history of planning in Ghana, very little has been documented on the subject of contemporary spatial planning in the academic literature (see e.g. Fuseini and 
Kemp 2015; Awuah et al. 2014). In view of this, we focus the current paper on the era of contemporary planning in Ghana. We choose the period after 1992 when Ghana adopted a constitutional rule and initiated a process of democratization and decentralization. Since this era marked the beginning of decentralized planning in Ghana and is much more recent, we are able to draw on the available, though rather fragmented, information from government records for our analysis of multi-level integration in planning in Ghana.

First, we consulted secondary sources of mainly reports, plans and legislations obtained from public sector institutions including the National Development Planning Commission, National Town and Country Planning Department and the Ministry of Local Governments. The main documents consulted were the following: National Development Planning Commission's Act (Act 479), National Development Planning (Systems) Act, 1994 (Act 480), Town and Country Planning Ordinance, 1945 (CAP 84), Draft Land Use and Spatial Planning Bill, 2011; Local Government Act, 1993 (Act 462) and the New Spatial Planning Model Guidelines and Manual for the Preparation of Spatial Plans issued by the Town and Country Planning Department. Based on these documents, we first established the key features of Ghana's decentralized planning system focusing mainly on understanding how the system is designed in theory to foster policy coherence and integration both vertically (i.e. between spatial scales) and horizontally (i.e. across sectors and policy domains).

With this background information, we arranged interviews with officials at the headquarters of the Town and Country Planning Department in Accra, Ghana. A key contact person in senior position at the headquarters of the department was designated to respond to our research questions on behalf of the TCPD. ${ }^{1}$ The interviews focused mainly on seeking clarification and understanding into the mechanisms of integration as built into the planning system in theory and integration in action. Over the past 8 years, under a new three-tier decentralized spatial planning model adopted in 2007, the department has overseen the preparation of a National Spatial Development Framework: two Regional Spatial Development Frameworks and several District framework plans, Structure Plans and Local land use/sub-division plans. In essence, we gathered primary information on the department's experiences with policy integration based on the ongoing pilot plan making and implementation processes at the national and sub-national levels. In addition to information obtained from these sources, we draw on our tacit knowledge on and experience with contemporary spatial planning in Ghana in discussing multi-level integration in the country's planning system.

\section{Discussion: Multi-Level Policy Integration in Ghana's Spatial Planning System}

The planning system comprises the evolving institutional and legal arrangements and the accompanying practices for the formulation and implementation of policies, plans

\footnotetext{
${ }^{1}$ The official in question had extensive experience and the relevant institutional memory having actively been involved in the on-going reforms that have led to the inception of the New Spatial Planning System. Also, the response elicited could easily be corroborated with information documented, sanctioned and made publicly available by the Ministry of Environment Science and Technology and Innovation and the Town and Country Planning Department.
} 
and projects. The formal governance structure determines the legal framework and institutional arrangements for spatial planning at the national and sub-national levels.

In view of this, we place the discussion on multi-level policy integration within the wider context of the national governance system in Ghana, focusing on the authorities and competencies for planning at the various scales of political administration.

\section{Governance Structure and Contemporary Planning in Ghana}

In 1992, Ghana adopted constitutional rule to steer the country into a new era of democratic governance and continuous process of decentralization. In 1993, the law on decentralization, Local Government Act (Act 462) was passed followed by the introduction of the National Development Planning System Act (Act 480) in 1994, to mark the inception of decentralized development planning.

Over the years, the country has evolved into a decentralized unitary state operating a three-tier governance system at the national, regional and local government levels of political administration. As shown in Fig. 1, the various institutions with authority and competences in planning correspond with the formal governance structure at the different scales. At the national level, sector ministries and agencies have planning competencies in their respective sectors including transportation, environment, education and health. The National Development Planning Commission (NDPC) established by an act of parliament - the National Development Planning Commission Act, 1994 (Act 479) functions as the co-ordinating body within the decentralized national Development Planning System.

At the regional level, there are 10 administrative regions with their respective Regional Coordinating Councils (RCCs), government agencies and departments. The RCCs do not necessarily exercise planning powers, instead, as specified in the Local Government Act (Act 462), they act as the regional administrative bodies that coordinate the activities of local governments. Under the administrative regions are Metropolitan, Municipal and District Assemblies (MMDAs). MMDAs derive their planning powers and competencies at the local level from the Local Government Act

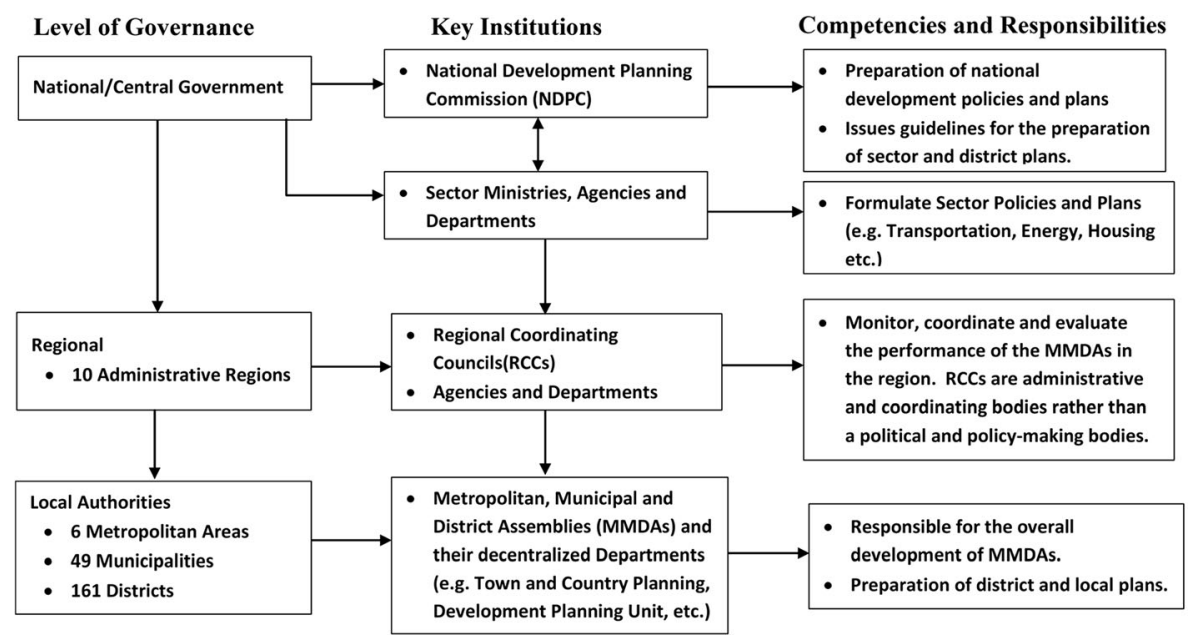

Fig. 1 Governance structure and institutional competences 
(Act 462) and National Development Planning System Act (Act 480). Their mandate is exercised through a number of decentralized departments including the Development Planning Unit and Town and Country Planning Department.

\section{An Established Tradition of 'Development' Planning with Less Emphasis on the 'Spatial'}

Since the advent of democratic governance in the early 1990s, Ghana has had the tradition of national level development planning as established in the National Development Planning (System) Act (Act 480). Over the past three and half decades, a number of medium-term National Policy Frameworks (NPFs) have been formulated by successive governments. The most recent of NPFs include the Growth and Poverty Reduction Strategy- GPRS I (2003-2005) and GPRS II (2005-2008) and Ghana Shared Growth and Development Agenda (2010-2013). NPFs mainly focus on socio-economic issues such as economic restructuring, macroeconomic stability and poverty reduction.

At the national level of policy formulation, the NDPC through a cross-sectoral planning group acts as the formal body that translate sectoral policies of the various ministries and agencies into medium-term NPFs. Thus, integration across policy domains and the accompanying institutions with competencies in planning is achieved through the co-ordinating role of the NDPC. Within this established system of Development Planning, local government authorities (i.e. MMDAs) are mandated to prepare Medium-Term Development Plans (MTDPs) covering their respective administrative jurisdictions. Both NPFs and MTDPs are medium-term plans with an overlapping horizon of 4 years. By design and in practice, national level visions and aspirations articulated in NPFs are translated by NDPC directly to MMDAs in the form of policy guidelines to which MTDPs must conform. The Development Planning Units (DPUs) of the MMDAs prepare the MTDP at the local level, and therefore serve as the focal point of policy co-ordination with the national level. Thus, through a top-down transfer in the form of policy guidelines, policy coherence and some form of conformity between the national and the local levels are achieved within the established Development Planning System.

Consistently however, NPFs have lacked in considerations of the spatial manifestations of their respective socio-economic visions as well as in specific policy goals aimed at planning and managing human settlements. Consequently, spatial planning over the years has been restricted to the traditional function of land-use zoning and development control at the level of the MMDAs, backed by a rather obsolete piece of legislation that predates the country's independence-the 1945 Town and Country Planning Ordinance (CAP 84).

Local land-use planning and development control are the mandate of the Town and Country Planning Department, a decentralized department under the MMDAs. Consequently, the concept of vertical integration and the accompanying formal arrangements of synchronising higher level land-use planning instruments with lower-level derivative instruments has been non-existent either by design or in practice in planning in Ghana. For years, no formally established channels of direct policy exchanges existed between the Town and Country Planning Departments at the local level, and the NDPC at the national level as has been the case with the DPUs. Instead, within this context, Structure 
Plans (SPs) which designate broad land-uses in urban areas and major cities constituted the highest tier of land-use planning instruments ever prepared. SPs were intended to provide the basis for the preparation of detailed sub-division plans often called sector layouts or local land-use plans. In practice, a handful of major urban centres including Accra, the capital city had SPs; at the moment, these SPs are outdated in years and in the principles of contemporary land-use planning.

Within the established tradition of development planning, policy integration between the 'spatial' and the 'socio-economic' is particularly weak at local level. This is because the two decentralized planning departments within the MMDAs exist and carry out their respective mandates almost in complete isolation from each other. Whereas the DPUs concentrate exclusively on preparing MTDP to tackle socio-economic problems, the Town and Country Planning Department focuses on land allocation and development control. Three major reasons explain this lack of horizontal co-ordination. First, whereas physical plans prepared by the Town and Country Planning Department have a longterm focus of 10 years or more, MTDPs prepared by the DPUs cover relatively shortterm period of 4 years. Thus, as far as the time dimension is concerned, the practical challenge of synchronising these two plans arises. Secondly, the lack of coordination is the result of the system of planning itself. The dearth of a spatial vision at the national level coupled with the severed interaction between the NDPC and the Town and Country Planning Departments at the local levels have over the years, established and perpetuated the notion that the 'spatial' is separate from the 'socio-economic' when in fact, the two are integrated and are together, essential to socio-economic transformation. Consequently, at the level of MMDAs, two separate planning committees exist for the purposes of co-ordinating and approving plans. Whereas Development Planning Subcommittees co-ordinate the process of MTDP preparation, the Statutory Planning Committees exercise co-ordinating and approval responsibilities over land-use plans.

Moreover, the concept of Regional planning, either at the level of the administrative regions or functional regions has never been pursued in Ghana even within the established Development Planning System. This is partly because the Regional Coordinating Councils, as explained earlier, do not have planning functions but exercise co-ordinating roles over the MMDAs. The National Development Planning (System) Act (Act 480), introduced the concepts of 'Joint-Development Planning Areas' where contiguous areas could be designated for planning purposes. However, the idea of jointly planning development has only existed as a concept in statutes without any experimental cases indicating how this could work in practice in terms of the institutional, legal and financial arrangements needed to support such an endeavour. So far, no experience exist with respect to a joint approach to planning either among MMDAs within the same administrative region or between any of the 10 administrative regions. In the absence of strategic regional planning, the opportunities to harness integrated policy formulation and implementation within and between regions, has by far been missed within the established Development Planning System.

\section{The Inception of Hierarchical Spatial Planning: One Country, Two Planning Systems?}

After years of neglect of spatial planning at the national and regional levels and a weak land use planning system at the local level, reforms were initiated in 2007 by the 
government of Ghana under the Land Use Planning and Management Project. Prominent among the reforms was the introduction of a decentralized Spatial Planning System based on a three-tier model of spatial planning instruments that correspond with the three-tier governance structure. These instruments are as follows: National Spatial Development Framework, Regional Spatial Development Framework and District Spatial Development Frameworks. Within this three-tier framework, derivative framework plans such as Sub-Regional Spatial Development Frameworks may be prepared. The concept of spatial development frameworks is defined in the National Spatial Planning System (NSPS) Module Guidelines as the following:

'..an indicative plan, showing the expected development over a fifteen to twentyyear period, which will include the location of key components of the strategy aimed at achieving the desired development' (MESTI, NSPS Module Guideline, 2011: p. 9)

Moreover, the new system, by design is intended so foster decentralized spatial planning and intergovernmental integration at various spatial scales which hitherto was non-existent. As the ministerial guidelines on spatial planning indicate, the key aim of the system is to:

'Provide a direct connection between national development strategies and the spatial realization of these strategies and local plans, through a 'chain of conformity'...each level of plan must be in conformity with the higher level plan" (MESTI, NSPS Module Guideline, 2011, p.8).

The reforms leading to the renewed emphasis on spatial planning at the national and sub-national levels have inevitably created a new situation of one country, two planning systems with the attendant challenges of policy integration. The new Spatial Planning System introduced in 2007 would exist alongside the established Development Planning System that was instituted in 1994. Whereas the latter derives legal backing from the National Development Planning (System) Act (Act 480), the former would receive legal backing from a new Land Use and Planning Bill — one of the key deliverables of the reforms. The proposed Bill, which is currently awaiting parliamentary approval, deploys a system of institutional arrangements for spatial planning separate and different from those under the established Development Planning System discussed under section 4.2. For example, the new Bill proposes the establishment of the Town and Country Planning Authority (TCPA), a body corporate to replace the existing Town and Country Planning Departments at the national, regional and local levels. As stated in the draft Bill, the TCPA would perform spatial, land use and human settlement functions of the national Development Planning System. The draft Bill also proposes a number of formal bodies including the Regional Spatial Planning Sub-Committee and the District Spatial Planning Authorities and their Sub-Committees as bodies exclusively responsible for spatial planning at the level of the administrative regions and MMDAs respectively.

Thus, implicitly, the notion of the 'spatial' being separate from the 'socio-economic' in planning still pervade policy thinking hence the perceived need to address them under separate legal and institutional arrangements. In fact, the 'development — spatial' 
dichotomy in planning exists at the Kwame Nkrumah University of Science and Technology where professional planners are trained. Within the university's department of planning, there are two separate undergraduate programmes: BSc. Development Planning - established in line with the introduction of the Development Planning System some two and a half decades ago and BSc. Human Settlement Planning-a relatively new programme established about a decade ago in the wake of reforms and renewed emphasis on spatial planning. Whereas graduates from the latter are trained specifically for the Town and Country Planning Departments to handle the task of landuse planning, graduates of the former are trained to handle the task of preparing MTDPs within the DPUs of the MMDAs (see Inkoom 2009).

This separation presents a number of challenges for effective integration, particularly at the regional and local levels. Firstly, by continuing to segregate the task of planning into 'spatial' and 'development' under separate governmental agencies, the reforms have rather reinforced and given a national character to a rather needless division which formerly manifested only at the local level. Although the proposed Technical Committees at the regional and local levels are intended to foster policy coordination across the 'spatial' and 'development' planning domains, we argue that the existence of two systems of planning would only further compartmentalize the task of planning into departments without resolving the barriers that for years have stifled effective horizontal policy co-ordination.

It is possible, given the current situation, to resolve the barriers of institutional coordination leading to weak policy integration through ad hoc and rather less formal arrangements. By this, the separate departments with planning competencies would agree to co-operate in executing the task of integrated planning. However, as years of experience have shown, effective policy co-ordination through ad hoc mechanisms and informal procedures cannot be guaranteed, particularly within the prevailing context of an established culture of policy divisions and exclusivity. Moreover, other fundamental problems exist that would hamper effective integration. Prominent among these is the time dimension required for effective integration. Whereas the new Spatial Planning System introduces framework plans that have long-term horizon, spanning a period of 20 years, the tradition of 4-year medium-term development planning at the national and local levels still exists and will continue under the established Development Planning System. Again, the practical challenge to synchronise a 20-year spatial development plan with a 4-year National Policy Framework and local governments Medium-Term Development Plans arises. Will spatial planning instruments now become the long-term strategic policy instruments that would inform medium-term policy frameworks at the national and local levels? Perhaps, this would be possible since a key requirement of Spatial Development Frameworks, according to the new Spatial Planning System Module Guidelines, is to capture and integrate the social, economic, environmental and the physical. However, one way by which this would have become the reality and translated into action, was if as part of the reforms, conscious attempts were made to bring the two seemingly competing systems of planning under one integrated planning system of institutions, legal frameworks and associated planning instruments at the various scales.

Furthermore, we identify that although Regional Spatial Development Frameworks have now been introduced at the regional scale of spatial planning, an equivalent plan focusing on socio-economic development as established within the tradition of 
Development Planning does not exist as one would expect at this level. Thus, within the current context of the one nation two planning systems, an important question remains: would the social and economic aspect of planning, long considered as being separate from the spatial dimensions, be neglected now that formal regional development planning, as understood from the established Development Planning System, does not occur at the regional levels? In principle, this would most likely not be the case as Regional Spatial Development Frameworks are supposed to be integrated frameworks that give attention to all aspect of development. However, if the concept of JointDevelopment Planning areas, as enshrined in the already established Development Planning System - which implicitly suggest some sort of regional planning for functional and or special regions - is to be implemented, then the notion and practice of regional development planning as separate from regional spatial planning would become established at level of the regions too. The result would be a duplication of efforts and a complete waste of valuable resources since the 'Joint-Development Boards' proposed by the National Development Planning Systems Act on the one hand, and the Regional Spatial Planning Committees to be established by the new Land Use Planning law on the other hand, would virtually be undertaking the same tasks of regional planning, but under different names, policy instruments with different legal backings. This would constitute a failure of policy integration as one key essence of integration is to avoid duplicity and wastages in scarce resources.

Similarly, below the regions, it will be a legal requirement under the new Spatial Planning System for MMDAs to formulate District Spatial Development Frameworks: integrated plans that capture all aspects and dimensions of development. With the exception of the new emphasis on referencing these new spatial planning instruments to specific locations and time frame, hence, the name Spatial Development Frameworks, they would not at all be different in content from the 4-year MTDPs that have longed been prepared by the MMDAs under the established Development Planning System. Thus, by allowing two planning systems to operate side-by-side and consequently compartmentalizing the task of planning in two separate departments at the level of the MMDAs, the current system has only created a recipe for unnecessary duplication of efforts and a waste of scarce resources at the local level. This would also constitute a major failure of effective integration across intuitional domains and between spatial scales at the level of the MMDAs.

\section{Muddling Through the New Three-Tier Spatial Planning System}

In keeping with the key deliverables of the LUPM project, a series of spatial planning instruments have been prepared with the dual aim of experimenting with and institutionalizing the concept of hierarchical spatial planning. This process has culminated in the formulation and adoption of the Western Regional Spatial Development Framework (WRSDF) and the Greater Kumasi Sub-Regional Spatial Development Framework (GKSRSDF) in 2012 and 2013, respectively, as well as several lower-tier framework plans. In mid-2013, the Town and Country Planning Department initiated the formulation of the National Spatial Development Framework in collaboration with the NDPC. We examine the current situation of policy integration in action by drawing on the experiences gained from these pilot projects as provided by our contact person at the Town Planning Department, hereafter anonymized as Senior Planning Officer. 
First, through the interviews with the Senior Planning Officer, it was identified that the various Spatial Development Frameworks (SDFs) formulated so far have not adhered to the ideal vision to create a 'chain of conformity' between plans, through a hierarchy of instruments from the national to the local levels. Instead, the formulation and adoption of the WRSDF and the GKSRSDF all predate the existence of the National SDF, which was in the final stages of completion as of the time of undertaking this research. The GKSRSDF covering eight MMDAs within the Ashanti Region (one of the 10 administrative regions) has been completed without an SDF for the wider region to date. Moreover, several District SDFs, Structure Plans and Local Plans within the geographic scope of these Regional SDFs were formulated in parallel with the preparation of the higher level instruments to which they are supposed to conform.

When asked about the reason(s) why lower level plans could be prepared without higher level instruments in a less coordinated manner than envisaged, the response was that:

'....the reality on the ground is that the piloting process of the new planning model has largely been donor-funded. These donors have particular interests that do not necessarily coincide with the coherence we envisaged in the planning model....the Norwegian government, for example, comes to say we have money to develop a plan for the Western Region... we accepted the offer and moved into it because at that time there was no funds or any arrangement for SDFs whether at the national or sub-national levels...That said, when it comes preparing the national level plans, we will make sure that plans that have been prepared out of order are integrated into National SDF accordingly' (Senior Planning Officer).

The above response highlights one major challenge to achieving policy coherence at least between spatial planning instruments at national and local levels: financing the plan formulation process itself. In the case of the WRSDF, it was clear that the recent discovery of oil in commercial quantities in the Western part of Ghana had necessitated the preparation of the plan. The plan preparation was financed by a grant from the Norwegian government under the Oil for Development (OfD) programme - a 5-year programme which begun in 2010 with the aim of strengthening the environmental management of the oil and gas sector in Ghana. At the same time as the WRSDF was being prepared, Tullow Oil and its partners, ${ }^{2}$ as part of their corporate social responsibilities, initiated the 'Town Planning: an Imperative for Sustainable Oil economy in Western Region' project under which funding was provided for the preparation of several lower-tier spatial development plans for selected urban centers in the oil and gas enclave of the Western region of Ghana. Similarly, the GKSRSDF was funded by the Japan International Cooperation Agency (JICA).

Thus, it becomes clear that in deciding the locations and scope of spatial development plans, some forms of compromise need to be reached whereby the prevailing interests of donor agencies and cooperate bodies, often disguised as financial and technical assistance, have to be aligned with local needs and strategic imperatives. The relative strengths of these actors (i.e. local technocrats and international donor

\footnotetext{
${ }^{2}$ Tullow Oil has since 2006 spearheaded the exploration and mining of crude oil offshore Ghana called the Jubilee Field. The company is currently one of the major operators in the Jubilee Field.
} 
agencies and corporations) in influencing critical decisions with respect to where and how spatial plans are prepared is not entirely clear. However, it appears that during the initial stages of experimentation, the funding sources have played a prominent role in determining the geography and scope of spatial plans. Consequently, the process of institutionalizing the new concept of hierarchical spatial planning has been quite chaotic, particularly in the oil and gas enclave, where different actors have sought to use spatial planning as a tool to asserting their influence and pursuing their cooperate interests in the emerging oil and gas economy. Although substantial funding for planning purposes have been released in the process, the concomitant proliferation of spatial development plans does not appear to have been well coordinated. Hence, the accompanying processes and products have also not necessarily been consistent with the coherence and conformity envisaged at the inception of the hierarchical spatial planning system.

Perhaps, the decision to start with relatively smaller spatial units below the national, was not dictated solely by the sources of finance, but in tandem with a more pragmatic consideration to start experimenting at these scales before transferring the experience to other regions and the national level. Even so, it becomes clear that appropriate financing systems for plan formulation would be essential to achieving policy coherence between scales in the future.

Moreover, it becomes clear from the Senior Planning Officer's response that in the interim, vertical integration between spatial planning instruments would assume a more cyclical and incremental approach by which lower level instruments that have been prepared and adopted would be synchronized in a bottom-up style with their corresponding higher level instruments.

In addition, the process of experimentation has proceeded without the key institutional arrangements required to support and co-ordinate it. This is because the key legislation (i.e. the Land Use and Planning Bill) as indicated earlier, has not come to force yet. Within the context of institutional and legislative void, a strategy of constituting Technical Oversight Committees comprising key Ministries, Departments and Agencies has been adopted. According to the Senior Planning Officer we interviewed, these Technical Oversight Committees have proved useful in coordinating the inputs of key actors and stakeholders in the formulation of the National SDF and the two Regional SDFs. The mandate of these committees however ends with the approval and adoption of the SDFs, leading to their dissolution. However, since effective integration is a continuous process that does not end with plan formulation, a major institutional challenge currently exists with the implementation process of the WRSDF and the GKSRSDF. Given that these plans cover spatial units comprising several neighbouring MMDAs, and in the absence of the necessary 'cross-boundary' institutional arrangements, the arrangements for implementation remain unclear to date. Currently, the practice of getting individual local authorities to build strategic alliance and collaborate in matters of strategic interests either through formally established rules or informal mechanisms remain completely unexplored.

Furthermore, although Regional Co-coordinating Councils exist, the interpretation of their mandate beyond their coordinating and regulatory roles over MMDAs remains vague (Crawford 2004). In terms of planning functions the Local Government Act (Act 462) establishing the Regional Co-coordinating Councils state 'A Regional coordinating Council shall perform the planning functions conferred on it by an enactment'. 
Currently, no such legal enactments have been invoked to this effect. Besides, given that Regional Co-coordinating Councils for years have not had any experience in strategic regional planning and implementation, their capacity to undertake this task at the invocation of a legal enactment also remains unclear.

The implementation strategies of both the WRSDF and GKSRSDF were crafted in anticipation of the new institutional arrangements that would accompany the Plans when the draft Land Use and Planning Bill comes into force. Consequently, the delayed passage of the Bill coupled with the absence of the relevant 'cross-boundary' institutions to oversee implementation has resulted in these Regional SDFs existing only in name without any real implementation action on the ground. Hopefully, these SDFs will not experience the fate of many others that have preceded them only to become historical artefacts in the archives of public sector agencies.

\section{Conclusion: Towards a Holistic View of Planning for Effective Multi-Level Integration}

In this paper, we set out to examine the key features of Ghana's planning system discussing the mechanisms for and challenges of multi-level integration across policy domains and between spatial scales. The analysis shows the planning system by design has several inbuilt features aimed at ensuring policy coherence at all levels. However, the gap between the ideal and the reality for policy integration remains wide with several inherently conflicting structures.

One of the main causes of weak policy integration is the nature of the planning system itself. We show how the combination of path dependence and reforms have created two distinctly separate planning systems that deploy separate institutional and legal arrangements as well as policy instruments to accomplish the task of planning. These are (1) the established Development Planning System instituted by the Development Planning Systems Act (Act) (Act 480) and decentralization Act-Local Government Act (Act 462) and (2) the new Spatial Planning Systems introduced in 2007 following reforms that aimed at instituting the concept of hierarchical spatial planning at the national, regional and local levels.

On the one hand, the established Development Planning System focuses on Development Planning narrowly defined as concerned with socio-economic transformation which emphasises poverty reduction at the national and local levels. Medium-term Policy Frameworks at the national level and Medium-Term Development Plans at the local levels with 4-year horizon are the main policy instruments under this system. Policy integration across institutional domains and between scales is achieved through the co-ordinating and plan formulation competencies of the NDPC. The new Spatial Planning System on the other hand, introduces the concept of hierarchical Spatial Development Frameworks that is supposed to take a more holistic and integrated approach to planning. Through a proposed Land Use and Planning Bill, it deploys a setup of institutions completely different from those existing under the established Development Planning system to accomplish the task of integrated spatial development planning. We argue that the pervasive notion that the 'spatial' is distinctly separate from the 'socio-economic' and hence the need to address them under separate legal and intuitional arrangements under two separate planning systems would only 
compartmentalize the task of planning, create unhealthy competition, result in a duplication of functions and ultimately stifle an integrated approach to policy planning.

Furthermore, we show that despite the long history of planning in Ghana, there is no tradition of middle level planning as the RCCs do not exercise planning competences but only provide co-ordinating roles between MMDAs under the established Development Planning System. The result has been the absence of strategic regional development planning and the accompanying institutional milieu that would ensure policy integration between the national level and the administrative regions, among MMDAs in the same administrative region and between different administrative regions on matters of strategic interest.

We acknowledge that planning systems throughout the world are not static and that although the current reforms particularly in the area of spatial planning are commendable, further reforms aimed at creating a unified planning system to accomplish the single task of integrated development planning should be pursued. Some form of institutional restructuring leading to a merger of agencies and departments with competencies in planning under the current situation of one country, two planning system would be necessary. Also, it would be essential to strengthen the capacity of regional bodies to effectively deliver the task of strategic regional development planning which has never existed in any form in the history of planning in Ghana. For the purposes of strategic regional development planning, the definition of the region should be reconsidered beyond just the current 10 regional administrative boundaries defined purposely for political administration.

Moreover, we identified several challenges hampering effective policy integration regarding the on-going experimentation with the new three-tier model of hierarchical spatial planning. Prominent among them is how the lack of appropriate financial arrangements has led to a system where foreign donor agencies have provided the much needed financial resources, but in doing so, have dictated and steered the planning process in directions that are not necessarily consistent with the coherence and conformity envisaged by the system. Systems to mobilize substantial funds domestically combined with programmes to building institutional capacity would be needed to establish control over the process of operationalizing the new spatial planning model. In addition, the current situation where several spatial development frameworks have been formulated at all levels without the accompanying institutions has stalled implementation. In the absence of these institutions ad hoc Over-sight Committees have provided the co-ordinating role in the plan formulation processes. These Committees however, were dissolved on the approval and adoption of the frameworks, creating an institutional void for implementation. The promulgation of the Draft Land Use and Planning Bill is needed urgently to address this problem.

Beyond this, formally established systems to ensure effective co-ordination between neighbouring MMDAs are lacking. Since policy integration is a continuous process that does not end with plan formulation, we recommend the need for systems aimed at encouraging and institutionalizing a culture of strategic alliance between neighbouring local authorities. We argue that such a collaborative culture cannot be guaranteed through informal and ad hoc approaches initiated on as-and-when-needed basis. Rather, the option of formally establishing the mechanism and approaches of strategic alliance through legally binding enactments should be considered. 
In conclusion, a new paradigm of integrated planning under a unified planning system is considered crucial to creating the fundamental conditions for effective multilevel policy integration in Ghana. The concept and practice of strategic regional planning should be embraced and the appropriate institutions setup in order to exploit the benefits of the void that has long existed between administrative regions and the national, between neighbouring regions and among local authorities within the same region. Finally, formally established collaborative mechanisms through legally binding enactments would be needed to institutionalize and enforce a culture of strategic partnerships in cross-cutting matters among local governments.

Open Access This article is distributed under the terms of the Creative Commons Attribution 4.0 International License (http://creativecommons.org/licenses/by/4.0/), which permits unrestricted use, distribution, and reproduction in any medium, provided you give appropriate credit to the original author(s) and the source, provide a link to the Creative Commons license, and indicate if changes were made.

\section{References}

Albrechts, L. (2006). Shifts in strategic spatial planning? Some evidence from Europe and Australia. Environment and Planning A, 38(6), 1149-1170.

Allmendinger, P. (2003). Re-scaling, integration and competition: future challenges for development planning. International Planning Studies, 8(4), 323-328.

Allmendinger, P. (2009). Planning theory (2nd ed.). New York: Palgrave Macmillan.

Allmendinger, P., \& Haughton, G. (2007). The fluid scales and scope of UK spatial planning. Environment and Planning A, 39(6), 1478-1496.

Allmendinger, P., \& Haughton, G. (2010). Spatial planning, devolution, and new planning spaces. Environment and Planning C: Government and Policy, 28(5), 803-818.

Awuah, K. G. B., Hammond, F. N., Lamond, J. E., \& Booth, C. (2014). Benefits of urban land use planning in Ghana. Geoforum, 51, 37-46.

Counsell, D., Allmendinger, P., \& Haughton, G. (2006). Integrated spatial planning- is it living up to expectations? Town and Country Planning-London-Town and Country Planning Association, 75(9), pp. 243-246. Available at: http://www2.hull.ac.uk/science/pdf/geogGH07d5.pdf. Accessed 20 Apr 2015.

Cowell, R., \& Martin, S. (2003). The joy of joining up: modes of integrating the local government modernisation agenda. Environment and Planning C: Government and Policy, 21(2), 159-179.

Crawford, G. (2004). Democratic decentralisation in Ghana: Issues and prospects. POLIS working paper, 9 , pp. 1-13. Available at; http://www.polis.leeds.ac.uk/assets/files/research/working-papers/wp9crawford. pdf. Accessed 20 Apr 2015.

Cullingworth, B., \& Nadin, V. (2006). Town and country planning in the UK (14th ed.). London: Routledge.

Davoudi, S., \& Evans, N. (2008). Territorial governance in the making. Approaches, methodologies, practices. Boletín de la A.G.E, 46, 33-52.

ESPON 2.3.2 (2006). Governance of territorial and urban policies from the EU to the local level, final report, ESPON, Available at; http://www.espon.eu. Accessed 20 Apr 2015.

Faludi, A. (2000). The performance of spatial planning. Planning Practice and Research, 15(4), 299-318.

Fuseini, I., \& Kemp, J. (2015). A review of spatial planning in Ghana's socio-economic development trajectory: a sustainable development perspective. Land Use Policy, 47, 309-320.

Healey, P., Khakee, A., Motte, A., \& Needham, B. (1997). Making strategic spatial plans: Innovation in Europe. London: UCL Press.

Inkoom, D. K. B. (2009). Planning Education in Ghana. Available at: http://www.unhabitat.org/grhs/2009. Accessed 30 July 2015.

Land Use and Planning Bill, submission of the further revised draft bill to the decentralization task force and the attorney-general's office, Town and country Planning Department, Accra, Ghana.

Meijers, E., \& Stead, D. (2004). Policy integration: what does it mean and how can it be achieved? A multidisciplinary review. In Berlin Conference on the Human Dimensions of Global Environmental Change: Greening of Policies-Interlinkages and Policy Integration. Berlin. 
Merritt, A., \& Stubbs, T. (2012). Incentives to promote green citizenship in UK transition towns. Development, 55(1), 96-103.

Ministry of Environment, Science and Technology (MESTI) (2011). The new spatial planning model guidelines, Accra Ghana.

Nadin, V. (2007). The emergence of the spatial planning approach in England. Planning Practice and Research, 22(1), 43-62.

Newman, P. (2008). Strategic spatial planning: collective action and moments of opportunity. European Planning Studies, 16(10), 1371-1383.

OECD (2001) Towards a new role for spatial planning. In Towards a new role for spatial planning. Paris: OECD Publishing.

Osborne, S. P. (2006). The new public governance? 1. Public Management Review, 8(3), 377-387.

Owens, S., \& Cowell, R. (2011). Land and limits: Interpreting sustainability in the planning process. London: Routledge.

Owusu, G. (2008). Indigenes' and migrants' access to land in peri-urban areas of Accra, Ghana. International Development Planning Review, 30(2), 177-197.

Peters, B. G. (1998). Managing Horizontal Government: the politics of co-ordination. Public Administration, $76(2), 295-311$.

Peters, B. (2006). Concepts and theories of horizontal policy management. Handbook of public policy (pp. 1821).

Roseland, M. (2000). Sustainable community development: integrating environmental, economic, and social objectives. Progress in Planning, 54, 73-132.

Rotmans, J., van Asselt, M., \& Vellinga, P. (2000). An integrated planning tool for sustainable cities. Environmental Impact Assessment Review, 20(3), 265-276.

Shaw, D., \& Lord, A. (2007). The cultural turn? Culture change and what it means for spatial planning in England. Planning Practice and Research, 22(1), 63-78.

Silva, E. A., \& Acheampong, R. A. (2015). Developing and Inventory and Typology of Land-use Planning Systems and Policy Instruments in OECD Countries (ENV/EPOC/WPIEEP (2015)8/FINAL). Paris, France: OECD. doi:10.13140/RG.2.1.3621.5767. Available at: http://www.oecd.org/officialdocuments/ publicdisplaydocumentpdf/?cote=ENV/EPOC/WPIEEP(2015)8/FINAL\&docLanguage=En. Accessed 29 Oct 2015.

Stead, D., \& de Jong, M. (2006). Practical Guidance on Institutional Arrangements for Integrated Policy and Decision Making, Geneva. Available at: http:/www.unece.org/fileadmin/DAM/thepep/documents/2006/ ece/ac_21/ECE-AC.21-2006-7-institutionalintegration.pdf. Accessed 20 Apr 2015.

Stead, D., \& Meijers, E. (2009). Spatial planning and policy integration: concepts, facilitators and inhibitors. Planning Theory \& Practice, 10(3), 317-332.

Underdal, A. (1980). Integrated marine policy: What? Why? How? Marine Policy, 4(3), 159-169.

UN-Habitat (2014). The State of African cities 2014: Re-imagining sustainable urban transitions.

United Nations (2008). Spatial planning - Key Instrument for Development and Effective Governance with Special Reference to Countries in Transition, New York and Geneva.

Vigar, G. (2009). Towards an integrated spatial planning? European Planning Studies, 17(11), 1571-1590.

Vigar, G., Healey, P., Hull, A., \& Davoudi, S. (2000). Planning, governance and spatial strategy in Britain: An institutionalist analysis. Basingstoke: Macmillan.

Yeboah, I.E.A. (2002). Demographic and housing aspects of structural adjustment and emerging urban form in Accra, Ghana. Africa Today (pp. 107-119). 